\title{
India's research council to undergo belated modernization
}

New Delhi

A REVAMPING of the Indian Council of Scientific and Industrial Research (CSIR) by an injection of young blood has been recommended by a committee set up 10 months ago by Mr Rajiv Gandhi, the prime minister. The committee has indicted the CSIR for its failure to help modernize Indian industry and has provided a new package of measures for invigorating its management and forging better links with industry.

Since he became prime minister, Gandhi has been critical of the functioning of CSIR, of which he is president. He feels that CSIR scientists have been reinventing the wheel rather than concentrating on mission-oriented projects or on technology to prepare India for the twenty-first century. A year ago, he showed his displeasure by replacing Dr S. Varadarajan, then director general of the CSIR, with Dr A.P. Mitra, a physicist who was previously director of the National Physical Laboratory. He then set up a seven-member panel headed by Mr Abid Hussian, a member of the Planning Commission, to review the work of the CSIR and to recommend changes to make it more responsive to the needs of industry.

The review is the fourth since CSIR was created, and the most critical. According to the committee, CSIR has lacked focus and direction and "has been unable to develop technologies which would meet even the most agonizing needs of our economy and society, let alone facilitate modernization". The major failure, it said, was the council's inability to transform scientific results in the laboratory into technology for industrial production.

In April 1986, CSIR had more than 1,000 projects under way. By putting emphasis on known products and processes, the council had failed to make a major impact. Declaring the CSIR system "unwieldy if not grotesque" the committee said that, by functioning like a department of government rather than as a society, it "has tended to foster hierarchy or bureaucracy and stifle creativity". The committee was also appalled by the "middle-age bulge"; most CSIR scientists are well over 40 years of age and have stayed simply because there has been no mechanism for firing the more unproductive scientists.

Lack of team work has also been criticized by the committee, which found the CSIR to be a "loose federation of different laboratories rather than a cohesive system working for concrete goals and specified objectives". The committee observed that the council and the industrial sector have acquired distorted images of each other; industry believes that CSIR is incapable of useful and timely research, while CSIR believes that "industries prefer the soft option of importing proven technology".

The committee's chief recommendations are aimed at bridging this gap. It has proposed that six of the nine members of the CSIR governing body should be from outside the CSIR. The chairman of the governing body should be an eminent professional scientist rather than, as at present, the CSIR director-general, and the governing body would relinquish its present role of administrative watchdog and focus more on formulating policy guidelines. The research councils of each

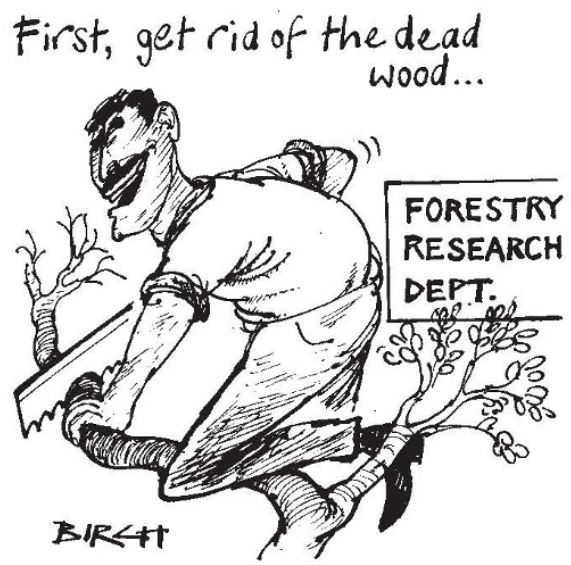

laboratory would similarly be reconstituted with members representing industry and consultancy organizations.

Some of the recommendations relate to personnel. The director's tenure would be fixed at six years, after which he would return to research work. The strength of non-scientific staff would be reduced by half in three years and promotion would no longer be automatic. The committee has asked CSIR to get rid of unproductive scientists by encouraging voluntary retirement on generous terms. To bring in new blood, CSIR should hire good scientists on six-year contracts "at salaries 50 per cent more than the usual". A scheme of visiting scientists and another of distinguished fellows have been suggested to improve the climate for research. And there should be an institute for retraining and reorienting the entire CSIR fraternity "which has been allowed to be denuded without being recharged".

All CSIR laboratories have been asked to take up research projects identified by users and to work together with private industry. The linkage would go beyond the customer-contractor relationship "through exchange of personnel and equipment". The link with public-sector companies should be ensured by associating CSIR technologists with the acquisi-
Respite for French researchers

\section{London}

RECRUITMENT of young French researchers, frozen since last June, is to start again in all disciplines but biology, the new science minister, Jacques Valade, has announced. His decision to renew appointments for life to France's leading research council, the Centre National de la Recherche Scientifique (CNRS), is seen by applicants for research posts as a major victory in their long-standing struggle with the government.

The move not only affects those eligible for the jobs available in 1987 . It also clarifies the position of the 285 young scientists deemed eligible last year, who were briefly promised jobs only to find their appointments invalidated by government decree (see Nature 324, 9, 1986). The 285, after extensive lobbying by their pressure group, the "Collectif des Admissibles", have had their one-year temporary contracts extended for life. In acting to restore the posts of the 1986 admissibles, Valade has managed to break the legal and political deadlock in the CNRS caused by the decision of his predecessor, Alain Devaquet, to overrule the 1986 appointments and to overhaul the appointment procedure.

Some problems still remain, however. Appointments in the life sciences remain blocked because of alleged 'irregularities' concerning the representation of the medical teachers' union on appointment committees. A decision is expected soon from the French high court. The admissibles have vowed to continue their campaign for permanent posts until the problems in biology are satisfactorily resolved, but, in the words of one CNRS spokesman, "at least everyone can breathe again".

Neil Crombie

tion by industry of imported technology "right from the beginning".

CSIR has also been asked to earn a third of its annual expenditure through consultancy to industry or government: the remainder would continue to come from public funds. In turn, industry has been asked to pay 0.75 per cent of the value of its output. This money could be used by industry to sponsor projects in CSIR laboratories.

The committee did take note of the achievements of the CSIR. Industrial production based on technology licensed by CSIR is now about $£ 250$ million. Some 50,000 tractors and a range of modern pesticides have been manufactured using CSIR expertise, and novel catalysts and petroleum-refining processes developed at CSIR have enabled India to emerge as a licensor in this high-technology field.

K.S.Jayaraman 